\title{
Correlação entre o Comportamento Termooxidativo do Polipropileno (PP) e do Polietileno de Baixa Densidade (PEBD) e o Tipo de Tratamento Superficial do Negro de Fumo
}

\author{
Edilene de Cássia D. Nunes, Alex S. Babetto e José Augusto M. Agnelli
}

Resumo: O Negro de fumo (NF) é muito utilizado como um aditivo fotoprotetor em polímeros termoplásticos, principalmente para o polietileno de baixa densidade (PEBD) e para o polipropileno (PP). O comportamento como estabilizante termooxidativo do negro de fumo modificado superficialmente foi estudado, completando sua caracterização como agente fotoestabilizante. A superfície do negro de fumo foi modificada através da oxidação com peróxido de hidrogênio e com ácido nítrico, a fim de aumentar o seu caráter ácido. Os resultados desta estabilização termooxidativa foram positivos para o PEBD, mas mostraram comportamento insatisfatório para o PP.

Palavras-chave: Negro de fumo, PEBD, PP, termooxidação, termoestabilização.

\section{Introdução}

Em função da relação custo/benefício, o negro de fumo (NF) é amplamente utilizado (quando a cor do produto permite) como aditivo fotoestabilizante em termoplásticos.

A literatura ${ }^{1-5}$ tem mostrado que o NF também apresenta propriedades termoestabilizantes e, quanto mais acentuado o caráter ácido do mesmo, melhor o desempenho como termoestabilizante em polietileno de baixa densidade (PEBD). A intensidade da degradação termooxidativa dos polímeros depende, principalmente, do coeficiente de difusão do oxigênio no polímero, da temperatura e da estrutura química da cadeia polimérica. Tanto o PEBD quanto o polipropileno (PP), apresentam em suas cadeias pon- tos suscetíveis à termooxidação, sendo estes, os hidrogênios ligados aos carbonos terciários e secundários. O PP e o PEBD são os termoplásticos que mais utilizam o NF como fotoestabilizante. Portanto, conhecer as propriedades do NF como termoestabilizante é um fator de grande importância na avaliação de uma formulação, quanto ao seu desempenho.

Desse modo, o objetivo deste trabalho foi analisar a influência do tratamento superficial do NF na sua ação como termoestabilizante e fotoestabilizante para o PP e para o PEBD.

\section{Experimental}

Materiais

Foram utilizados o polietileno de baixa densidade PB530 da OPP Petroquímica S.A., índice de flui- 
dez de $0,13 \mathrm{~g} / 10 \mathrm{~min}$ e densidade de $0,919 \mathrm{~g} / \mathrm{cm}^{3}$ e o polipropileno Bras-Fax 6331 da OPP Petroquímica S.A., índice de fluidez de $11 \mathrm{~g} / 10 \mathrm{~min}$ e densidade de $0,905 \mathrm{~g} /$ $\mathrm{cm}^{3}$. Com relação ao Negro de fumo, utilizou-se o STATEX N 220, tipo fornalha, da Copebrás S.A., com tamanho de partícula de $20-25 \mathrm{~nm}$, na concentração $2,5 \%$. Para a reação de oxidação superficial do negro de fumo utilizou-se peróxido de hidrogênio, $30 \%$ em peso, e ácido nítrico, puro para análise, $70 \%$ em peso.

\section{Equipamentos}

Os equipamentos utilizados nesta análise foram o Calorímetro Diferencial de Varredura (DSC) 2910 da Du Pont Instruments, com uma vazão de oxigênio de $60 \mathrm{~cm}^{3} /$ min., para a obtenção do tempo de indução oxidativa (OIT), e o equipamento de envelhecimento artificial acelerado, tipo Atlas Weather-Ometer, modelo 65/XW-WR1, operando com lâmpada de arco xenônio de 6500 watts.

\section{Metodologia}

Realizou-se dois tratamentos diferentes do negro de fumo $\mathrm{N}$ 220: com ácido nítrico $\mathrm{HNO}_{3}{ }^{2}$ e com peróxido de hidrogênio $\left(\mathrm{H}_{2} \mathrm{O}_{2}\right)^{3}$. A reação envolvida no processo é de oxidação da superfície do NF, visto que os dois reagentes são fortes agentes oxidantes.

Para os dois tratamentos, a reação foi realizada num reator de aço inoxidável, onde eram colocados o agente de oxidação e o negro de fumo, numa determinada proporção. A seguir, o reator era aquecido desde a temperatura ambiente até a temperatura de reação. A Tabela 1 mostra as condições de reação para os dois tratamentos.

Tabela 1: Condições de reação para os tratamentos do negro de fumo.

\begin{tabular}{cccc}
\hline $\begin{array}{c}\text { Agente } \\
\text { oxidante } \\
(\mathrm{AO})\end{array}$ & $\begin{array}{c}\text { Razão } \\
\text { AO:NF } \\
(\text { em peso) }\end{array}$ & $\begin{array}{c}\text { Temperatura } \\
\left({ }^{\circ} \mathrm{C}\right)\end{array}$ & $\begin{array}{c}\text { Tempo de } \\
\text { reação } \\
\text { (horas) }\end{array}$ \\
\hline $\mathrm{HNO}_{3}$ & $7: 1$ & $100 \pm 3^{\circ} \mathrm{C}$ & 4 \\
$\mathrm{H}_{2} \mathrm{O}_{2}$ & $4: 1$ & $50 \pm 3^{\circ} \mathrm{C}$ & 2 \\
\hline
\end{tabular}

Após a reação, o sistema foi resfriado até a temperatura ambiente. Para eliminar o excesso dos agentes oxidantes que não reagiram com o $\mathrm{NF}$, realizou-se a lavagem com água destilada do sistema $\mathrm{AO} / \mathrm{NF}$, até que o $\mathrm{pH}$ da água de lavagem atingisse um valor constante, assegurando-se assim, que os $\mathrm{AO}$ foram completamente eliminados do sistema. A seguir, o NF foi colocado em uma estufa a uma temperatura de $50^{\circ} \mathrm{C}$, para secar e ser, posteriormente, utilizado nas formulações.

Após o tratamento dos dois NF, realizou-se a incorporação destes aos polímeros, sendo adicionado $2,5 \%$ em todas as formulações, inclusive quando foi utilizado o NF não tratado (NF comercial).

\section{Resultados}

O monitoramento da termooxidação foi realizado através do tempo de indução oxidativa (OIT) obtido por Calorimetria Diferencial de Varredura (DSC). Os resultados obtidos estão apresentados na Tabela 2 e na Figura 1.

Tabela 2: Valores de OIT do PP e do PEBD contendo 2,5\% de negro de fumo (NF), em função do tratamento do NF; massa das amostras entre 6 e $8 \mathrm{mg}$.

\begin{tabular}{lc}
\hline \multicolumn{1}{c}{ Formulações } & OIT(min) \\
\hline $\begin{array}{l}\text { PP + NF comercial } \\
\text { não tratado }\end{array}$ & $5,4 \pm 0,3$ \\
PP + NF tratado & $4,9 \pm 0,1$ \\
com $\mathrm{HNO}_{3}$ & \\
$\mathrm{PP}+\mathrm{NF}_{\text {tratado }}$ & $2,5 \pm 0,2$ \\
com $\mathrm{H}_{2} \mathrm{O}_{2}$ & \\
PEBD + NF & $2,9 \pm 0,4$ \\
comercial não tratado & \\
PEBD + NF tratado & $54,4 \pm 2,3$ \\
com $\mathrm{HNO}_{3}$ & \\
PEBD + NF tratado & $74,5 \pm 0,4$ \\
com $\mathrm{H}_{2} \mathrm{O}_{2}$ & \\
\hline
\end{tabular}

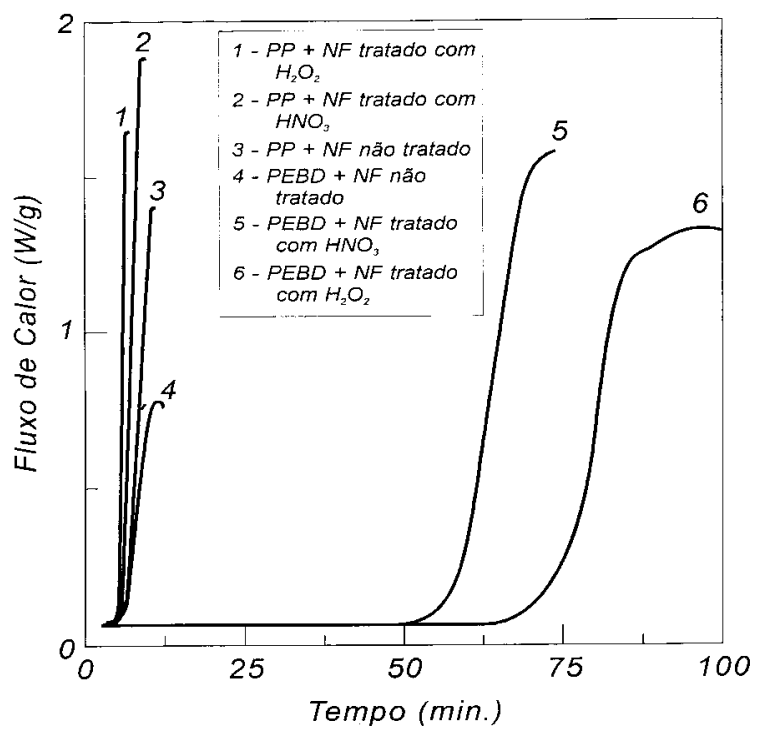

Figura 1: Curvas de fluxo de calor diferencial em função do tempo, para tratamentos isotérmicos a $210^{\circ} \mathrm{C}$ para o $\mathrm{PP}$ e a $190^{\circ} \mathrm{C}$ para o $\mathrm{PEBD}$. 


\section{Discussão e Conclusões}

Com relação ao PP, a oxidação do $\mathrm{NF}$ com $\mathrm{HNO}_{3}$ provocou uma pequena queda no OIT, enquanto que a oxidação com $\mathrm{H}_{2} \mathrm{O}_{2}$ reduziu em mais de $50 \%$ o OIT relativo à formulação com NF não tratado.

Para o PEBD, a utilização de NF tratado com $\mathrm{HNO}_{3}$ causou um aumento de mais de 18 vezes no valor do OIT, quando comparado com o da formulação com NF não tratado, enquanto que a utilização do NF tratado com $\mathrm{H}_{2} \mathrm{O}_{2}$, causou um aumento de mais de 25 vezes no OIT, com relação ao valor para o NF não tratado.

Comparando-se os resultados, para o $\mathrm{PP}$ e para o PEBD com NF tratados, quanto ao comportamento dos NF modificados, pode-se dizer que os óxidos de superfície dos NF atuam de forma diferencial, na termooxidação para o PP e o PEBD.

Este efeito deve estar relacionado com a estabilidade relativa dos complexos radicalares do NF/PEBD e NF/PP. Sabe-se que o NF interage com radicais livres da seguinte forma:

$$
\mathrm{NF}+\mathrm{R}^{\bullet} \rightarrow(\mathrm{NF}-\mathrm{R})^{\bullet}
$$

O complexo (NF-R) é é efetivo quando o mesmo apresenta estabilidade suficiente para inibir o processo oxidativo de degradação. Para o PEBD o complexo (NF-PEBD) 'é mais estável que o radical proveniente do PEBD e, consequentemente, estável o suficiente para inibir o processo oxidativo, enquanto que no PP, o complexo (NF-PP) é menos estável que o radical derivado do PP e, assim, não se observa a formação do complexo.

Desta forma, o macrorradical de PP permanece suscetível à degradação oxidativa e, neste caso, ocor- re a termooxidação, comprovada pelos baixos valores para o tempo de indução oxidativa (OIT).

Desse modo, dos resultados obtidos concluiu-se que:

- para o PEBD, o negro de fumo tratado auxilia os antioxidantes na prevenção de processos termooxidativos.

- para o PP o desempenho dos NF tratados foi inferior ao do NF comercial não tratado, não sendo indicado como aditivo em processos termooxidativos.

\section{Referências Bibliográficas}

1 - Gilroy, H. M.; Chan, M. G. - "Effect of pigments on the ageing characteristics of polyolefins" Polymer Science and Technology, 26, 273-287, 1984.

2 - Obuknov, V. M.; Shelomentseva, I. V.- "Oxidative modification of carbon black"- Plenum Publishing Corporation, 2308-2310, 1988.

3 - Giliazetdinov, L. P.; Romanova, V. I.; Lutokhina, A. S.; Safronova, I. M.; Tsygankova, E. I. "Oxidative modification of surface of carbon black" - Zh. Prinkl. Khim., 29 (49), 420-424, 1976.

4 - Ojeda, T.; Liberman, S.; Amorin, R.; Samios, D. "Influência do teor de etileno sobre as propriedades físicas de copolímeros propileno-etileno" - Química Nova, 19 (3), 242-247, 1996.

5 - Mani, R.; Singh, R.P.; Sivaram, S. - "Ethylenepropylene Copolymers: some aspects of thermal - and photo - degradation and stabilization" Trends in Polymer Science, 1 (10), 322-328, 1993. 